\title{
Status of bacterial leaf streak of corn in the United States
}

\author{
Kirk Broders, assistant professor, Bioagricultural Sciences and Pest Management, \\ Colorado State University
}

The bacterial pathogen Xanthomonas vasicola pv vasculorum (Xvv), which causes the disease bacterial leaf streak (BLS), was officially reported on maize in the U.S. in 2016 (Korus et al. 2017). This represents the first report of this disease in North American and is the only report of the disease anywhere in the world outside of South Africa. The disease was observed in 51 counties in Nebraska as well as 6 counties in eastern Colorado and 16 counties in western Kansas. The disease has continued to expand in 2016 reaching epidemic proportion in regions of Colorado, Kansas and Nebraska with several fields reporting disease incidence levels above $90 \%$ and disease severity reaching greater than $50 \%$ of leaf area infected. This level of disease will likely have an impact on yield. The disease was also recently identified from maize fields in Iowa, Illinois, Oklahoma, South Dakota and Texas. The rapid penetration of Xvv into the U.S. maize production region combined with a lack of management methods has created a critical and urgent need for research and engagement with affected producers and allied industry.

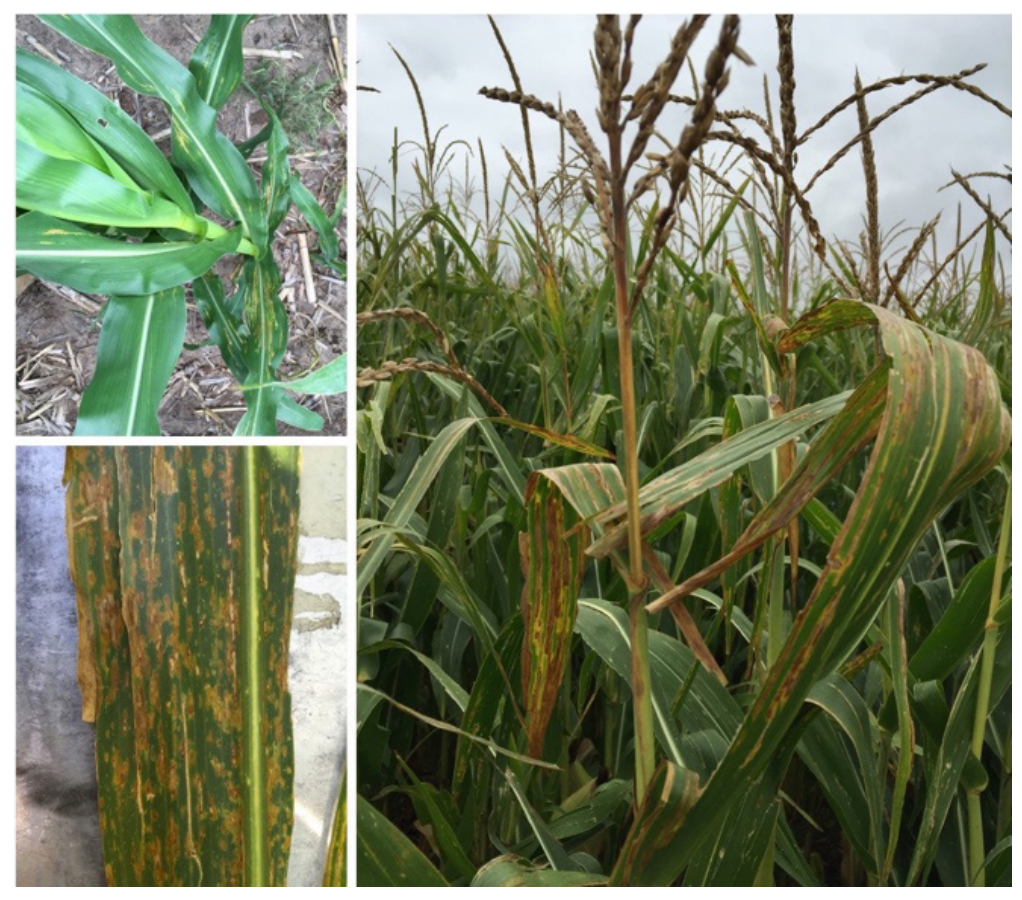

Figure 1. Symptoms of bacterial leaf streak caused by $X v v$ early in the season on lower leaves (upper left) and later in the season on the upper third of the plant (lower left, right)

$X v v$ causes bacterial leaf streak (BLS), which is primarily a foliar disease of corn. Growers in southwestern Nebraska first began to notice symptoms of BLS as early as 2014. The disease was observed to be the most severe in semi-arid regions, such as western Nebraska, western Kansas and eastern Colorado, under centerpivot irrigation and in continuous corn production systems. Early symptoms began to appear at the V4 growth stage on lower leaves (Figure 1). It is likely the bacteria are splashed by rain or irrigation water onto these lower leaves. As the season progresses, the disease continues to move throughout the field and into 
the upper canopy, likely due to recurrent overhead irrigation or rain. Significant long-distance dispersal has also been observed in fields where no early or mid-season infections were observed, but after strong thunderstorms, severe symptoms were observed in the upper canopy (Figure 1). The combination of warm weather with periodic overhead irrigation and ample residue for survival of $X v v$ has likely amplified the outbreak of BLS in this region as the climatic and production conditions appear optimal for Xvv infection and reproduction.

The only information pertaining to this disease on maize has come from work done in South Africa, which primarily investigated host range on other African crops, such as sugarcane and banana. We therefore have very limited information on how this pathogen infects it's host, what plant tissue(s) it is capable of infecting, how the pathogen survives the winters, where initial inoculum comes from at the beginning of each crop season, how the bacteria spreads from plant to plant and long distance, what climatic variables favor disease development and spread, how many other plant species Xvv is capable of infecting or using as alternate hosts, and if this bacteria will be able to persist and thrive in all corn growing regions of the U.S.

\section{Effort to develop new epidemiological models for Xanthomonas vasicola pv. vasculorum}

Since Xvv was first reported in the U.S. researchers at CSU, University of Nebraska and Iowa State University have been leading an effort to describe the disease (Korus et al. 2017), survey the extent and distribution of the disease, develop early detection methods (Lang et al. 2017), assess severity of the disease, and provide outreach programs designed to educate growers (Robertson et al. 2017). Through these efforts, we have established that the most significant levels of BLS have been observed in the region encompassing northeastern Colorado, southeastern Nebraska and northwestern Kansas, which is where first reports of the disease were made in 2014 and 2015 (Figure 2). During the 2016 production year, a significant eastward spread of the disease was observed as reports of BLS were confirmed in Iowa, Illinois, Oklahoma, South Dakota and Texas (Figure 2).

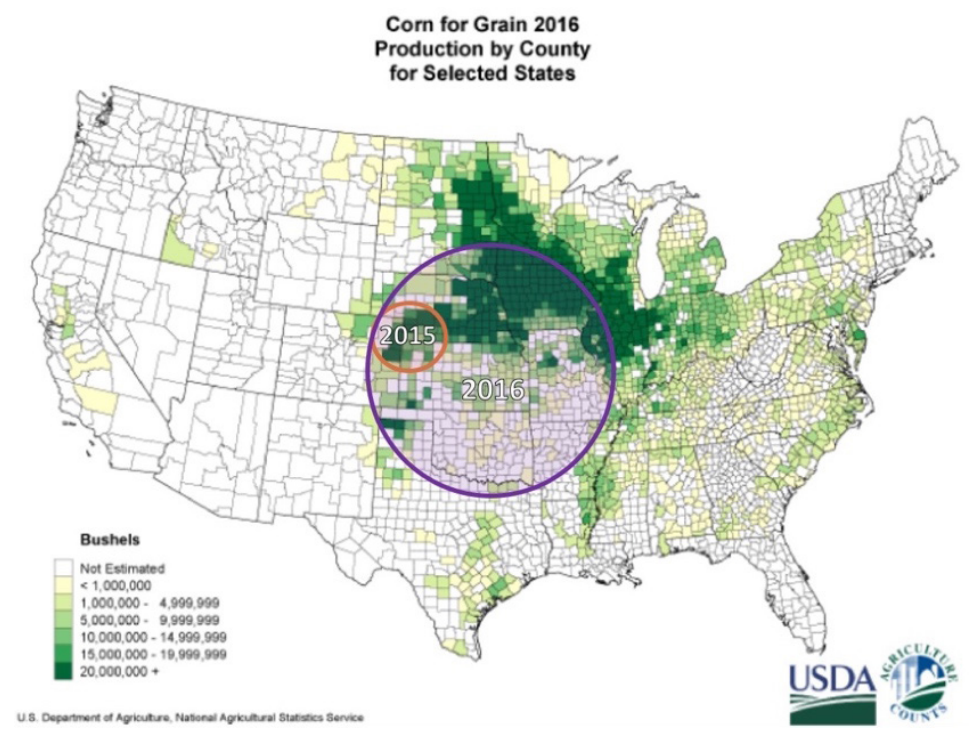

Figure 2. Distribution of BLS during 2015 and 2016 based on confirmed identification of Xvv from infected leaf tissue. Not all counties within the 2016 radius had positive confirmations of Xvv, but fall within the range of the most east, west, north and south locations with positive identifications, and therefore represent the potential distribution of BLS

In addition to monitoring the spread of this disease, work in the lab of Dr. Broders has focused on understanding the evolutionary history of $X v v$ and how it may have arrived to the US. BLS was first described in 1949 on corn in South Africa (Dyer 1949), but prior to 2016 it had not been documented 
in the USA (Korus et al. 2017). Due to the importance of corn in the USA, and the implications of the emergence and spread of a new disease, accurate identification of the causal agent and determination of its relationship to the strains from South Africa are of critical importance to the corn industry. The only other report of BLS of corn outside of South Africa and the U.S. is Argentina (Plazas et al. In Review). Dr. Broders is collaborating with researchers at the Universidad Católica de Córdoba in Cordoba, Argentina, regarding symptoms on maize they believed to be BLS. Bacteria were isolated from symptomatic leaves and then shipped to the Broders lab, where seven of the bacterial isolates were determined to be Xvv. While the official report of the disease in Argentina is relatively recent, the symptoms of BLS were first observed in 2010 in Cordoba province and have since spread to the other nine provinces where maize is grown (Plazas et al. In Review). In order to understand the evolutionary history of maize Xvv isolates, we sequenced the genomes of 23 isolates recovered from maize in the U.S., Argentina and South Africa. We then compared these to isolates recovered from sugarcane, sorghum and Tripsicum laxum, a wild relative of maize. We found that Xvv isolated from maize in Argentina, South Africa and the US forms a distinct genetic group from isolates infecting sugarcane and T. laxum (Figure 3). The preliminary analysis indicated there is greater diversity among isolates of $X v v$ from Argentina than isolates from South Africa and the U.S. (Figure 3). This would suggest $X v v$ has been present in Argentina longer than previously thought. It also seems likely that the strain of $X v v$ introduced into the US is more similar to isolates from Argentina than South Africa. However, greater sampling density of $X v v$ in South Africa is currently in progress order to provide a more definitive answer on where strains from the US originated

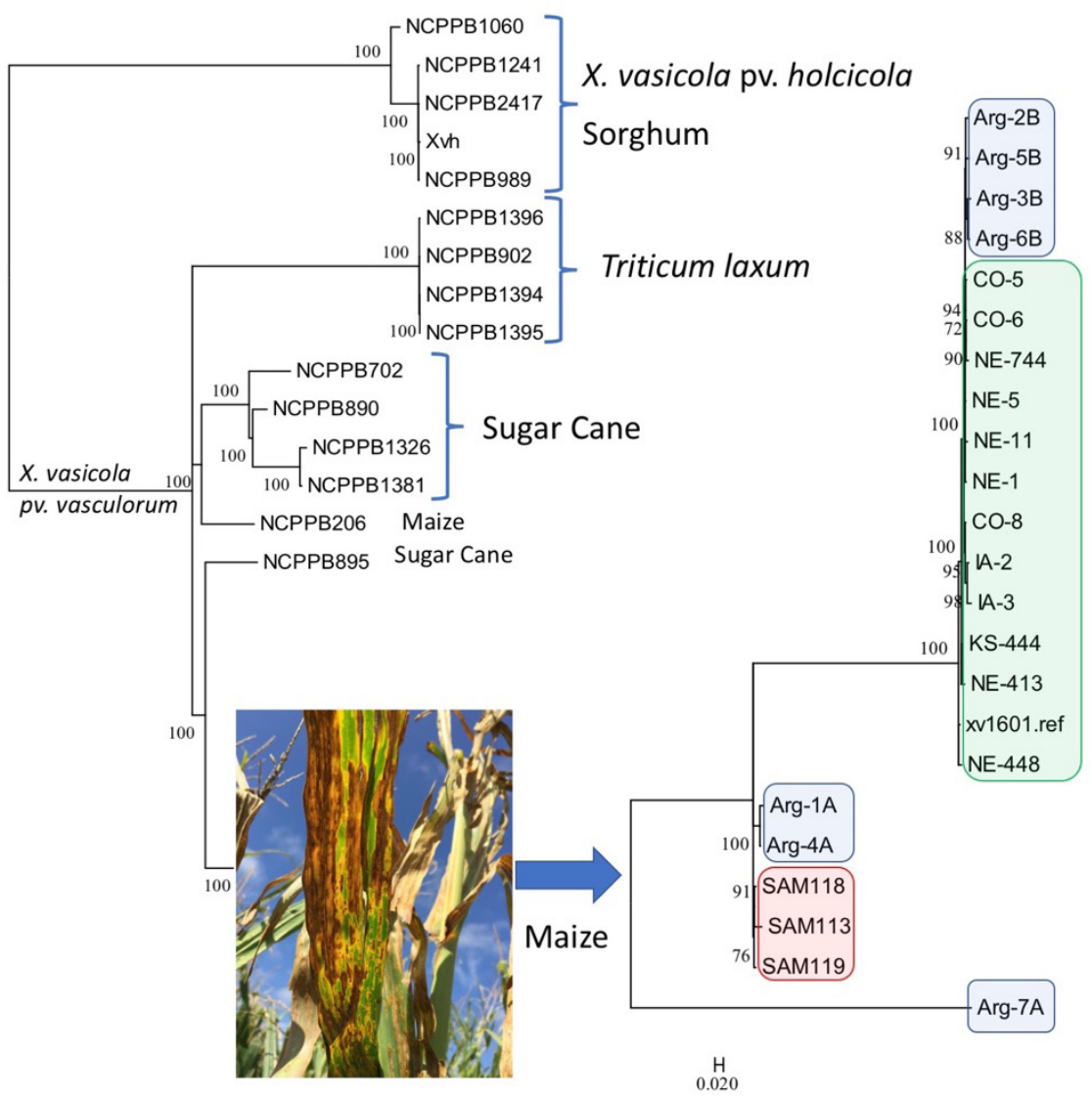

Figure 3. Whole genome phylogeny of $X$. vasicola isolates recovered from sorghum, T. laxum, Sugar cane and Maize. Isolates from Argentina, South Africa and US are highlighted in blue, red and green, respectively. 
The maize growing regions where BLS is present in Argentina, South Africa and the U.S. share several similarities. BLS seems to be most prevalent in semi-arid to dry subhumid production regions in Argentina, South Africa and the United States often located at elevations near 3000 feet above sea level and between $28-40^{\circ}$ from the equator (Figure 4). These regions experience similar growing conditions with hot, dry summers with occasionally intense thunderstorms. We have several hypotheses that may explain this phenomenon. First, semi-arid maize production often requires some type of irrigation, most frequently overhead irrigation. We believe the combination of warm temperatures and frequent overhead irrigation creates an ideal environment for this disease to reach epidemic levels. This has certainly been the case in the U.S. where the most significant levels of disease have been observed in eastern Colorado and western Nebraska where the majority of the corn is under center-pivot irrigation and the climate is more arid. In the case of Argentina, much of the corn is grown without irrigation, but summers are hot and the area is prone to thunderstorms that produce strong winds and hail, which may be important for disease spread. $X v v$ may be very well-adapted to thrive in these hot, dry climates where periodic wind, rain and irrigation allow it to spread.
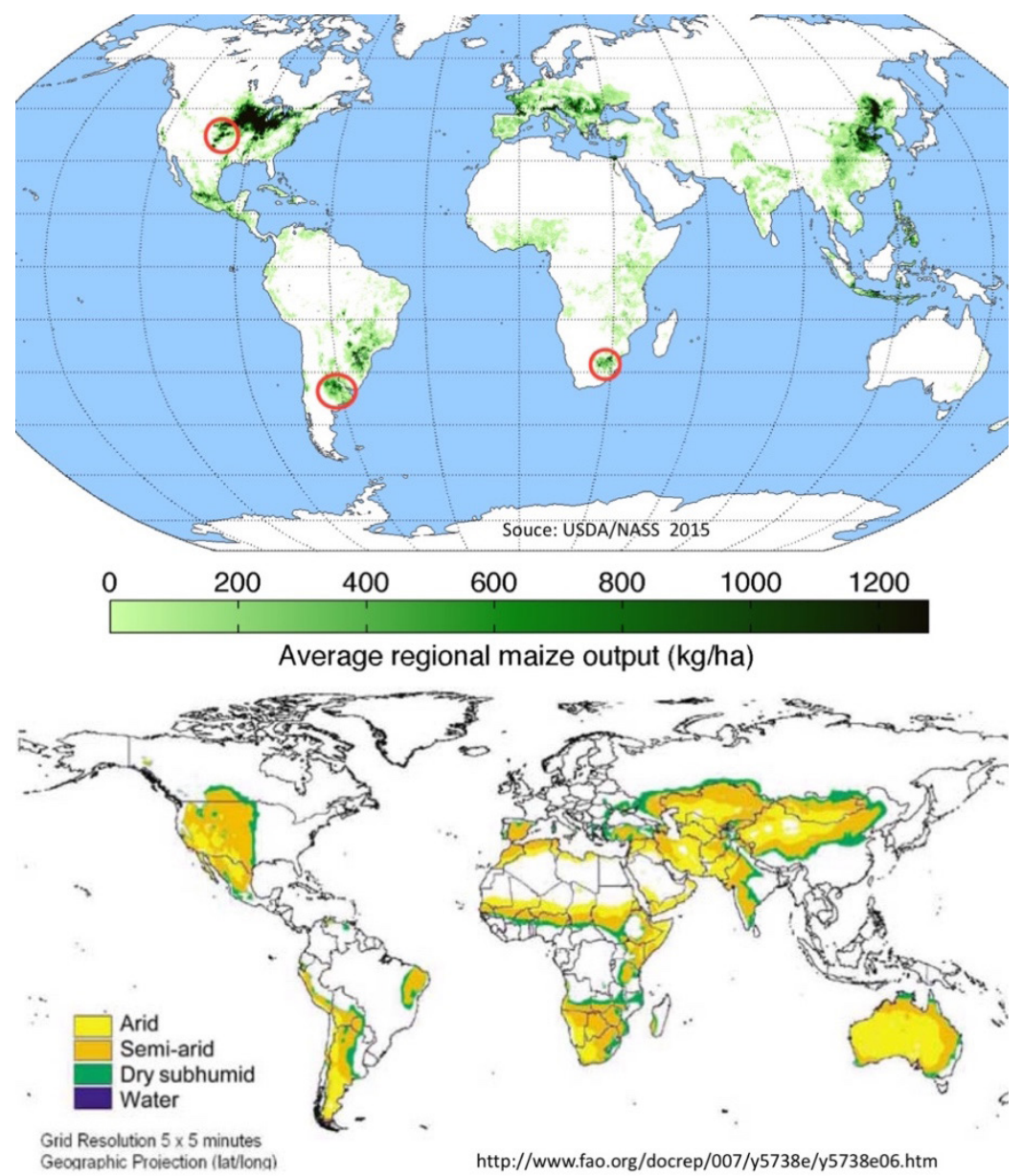

Figure 4. Global distribution of confirmed Xvvinfections of maize causing BLS (red circles) in relation to global maize production and distribution of semi-arid and dry subhumid production regions

There are few effective methods for management of Xanthomonas in the field. Little is known about the effective management of BLS in maize. To date, there is no chemical control commercially available 
for BLS. While cultural control measures are likely to offer some degree of control of BLS by decreasing the amount of primary inoculum present, further study is required. Preliminary data suggests that varietal resistance exists, indicating management may be possible through host resistance. Because of the limited amount of information available for BLS control, we must look to related crop species to examine which management methods might be successful for Xvv. For bacterial leaf streak of sorghum which is caused by $X$. v. pv. holcicola, resistant varieties are the main method of disease control, followed by cultural methods including rotation and weed control (Janse 2005). Currently little is known about host resistance to BLS. BLS can be severe on grain corn, sweet corn and popcorn, indicating there is susceptibility in all types of maize germplasm and maize varieties need to be evaluated and improved for BLS so that susceptible germplasm is not released. In order to query host resistance, it is necessary to evaluate populations to demonstrate that sufficient phenotypic variation exists in order to provide the raw material to breed for resistance. Once phenotypic variation is shown to exist, alleles for resistance and susceptibility can be identified. After identification of resistant alleles, favorable alleles need to be incorporated into breeding programs and detrimental alleles purged.

The overall goal of this presentation is to provide a better understanding of the basic disease ecology and epidemiology of $X v v$, and explain to growers how this information will be used to develop new decision support tools, resistant varieties and extension material to assist growers in managing this disease.

\section{References}

Dyer RA. Botanical surveys and control of plant diseases. Farming in South Africa. Annu Rep Dep Agric South Afr. 1949;275: 119-121.

Janse, J. D. (2005). Phytobacteriology: principles and practice, Cabi.

Korus K, Lang J, Adesmoye AO, et al. (2017) First report of Xanthomonas vasicola causing bacterial leaf streak on corn in the United States. Plant Disease, 101, 1030.

Lang J, DuCharme E, Ibarra-Caballero J, et al. (2017) Detection and characterization of Xanthomonas vasicola pv. vasculorum (Cobb 1894) comb. nov. causing bacterial leaf streak of corn in the United States. Phytopathology, In Press.

Plaza MC, De Rossi RL, Brucher E, Guerra FA, Vilaro M., Guerra GD, Wu G., Ortiz-Castro MC, Broders K. (2017) First report of Xanthomonas vasicola pv. vasculorum causing bacterial leaf streak of maize (Zea mays L.) in Argentina

Robertson A, Broders K, Jackson TA, et al. (2017) Bacterial Leaf Streak. Crop Protection Network, CPN2008. http://cropprotectionnetwork.org/corn/cpn-2008-bacterial-leaf-streak/. 